\title{
Improving the workability and rheological properties of Engineered Cementitious Composites using factorial experimental design
}

\author{
Mustafa Şahmaran $^{\text {a,* }}$, Zafer Bilici ${ }^{\mathrm{a}}$, Erdogan Ozbay ${ }^{\mathrm{b}}$, Tahir K. Erdem ${ }^{\mathrm{c}}$, Hasan E. Yucel ${ }^{\mathrm{a}}$, \\ Mohamed Lachemi ${ }^{\mathrm{d}}$ \\ ${ }^{a}$ Department of Civil Engineering, Gaziantep University, Gaziantep, Turkey \\ ${ }^{\mathrm{b}}$ Department of Civil Engineering, Mustafa Kemal University, Antakya, Turkey \\ ${ }^{\mathrm{c}}$ Department of Civil Engineering, Izmir Institute of Technology, Izmir, Turkey \\ ${ }^{\mathrm{d}}$ Department of Civil Engineering, Ryerson University, Toronto, Canada
}

\section{A R T I C L E I N F O}

\section{Article history:}

Received 8 February 2012

Received in revised form 25 August 2012

Accepted 31 August 2012

Available online 11 September 2012

\section{Keywords:}

A. Fibers

B. Rheological properties

B. Mechanical properties

A. Discontinuous reinforcement

Engineered Cementitious Composites

\begin{abstract}
A B S T R A C T
In the development of Engineered Cementitious Composites (ECC), micromechanics-based design theory is adopted to properly select the matrix constituents, fiber, and fiber-matrix interface properties to exhibit strain hardening and multiple cracking behaviors. Despite the micromechanics design constraints, practical applications show that the workability and rheological properties of matrix can affect the fiber dispersion uniformity, which have also direct concerns on composite mechanical properties. For this reason, in this research, parameters of micromechanics-based optimized ECC mixture design, which most possibly affecting the workability and rheological properties, are investigated. An experimental program that contains 36 different ECC mixtures was undertaken to quantitatively evaluate the combined effects of the following factors on workability and rheological properties: water-binder (w/b), sand-binder (s/b), superplasticizer-binder $(\mathrm{SP} / \mathrm{b})$ ratios and maximum aggregate size $\left(D_{\max }\right)$. A mini-slump cone, a Marsh cone and a rotational viscometer were used to evaluate the workability and rheological properties of ECC mixtures. Compressive strength and four point bending tests were used for mechanical characteristics of ECC mixtures at 28 days. The effects of studied parameters ( $\mathrm{w} / \mathrm{b}, \mathrm{s} / \mathrm{b}, \mathrm{SP} / \mathrm{b}$ and $\left.D_{\max }\right)$ were characterized and analyzed using regression models, which can identify the primary factors and their interactions on the measured properties. Statistically significant regression models were developed for all tested parameters as function of $\mathrm{w} / \mathrm{b}, \mathrm{s} / \mathrm{b}, \mathrm{SP} / \mathrm{b}$ and $D_{\max }$. To find out the best possible ECC mixture under the range of parameters investigated for the desired workability and mechanical characteristics, a multi-objective optimization problem was defined and solved based on the developed regression models. Test results indicate that $\mathrm{w} / \mathrm{b}, \mathrm{s} / \mathrm{b}$ and $\mathrm{SP} / \mathrm{b}$ parameters affect the rheological and workability properties. On the other hand, for the range of studied aggregate sizes, $D_{\max }$ is found to be statistically insignificant on the rheological and workability properties of ECC.
\end{abstract}

(c) 2012 Elsevier Ltd. All rights reserved.

\section{Introduction}

During the last decade concrete technology has been undergoing rapid development. The effort to modify the brittle behavior of plain cement materials such as cement pastes, mortars and concretes has resulted in modern concepts of high performance fiber reinforced cementitious composites (HPFRCCs) that exhibit ductile behavior under uniaxial tension load. HPFRCC promises to be used in a wide variety of civil engineering applications, as summarized in Japan Concrete Institute and by Kunieda and Rokugo [1,2]. One of the most promising areas of application of this material is in the repair and strengthening of concrete structures. Several

\footnotetext{
* Corresponding author.

E-mail address: sahmaran@gantep.edu.tr (M. Şahmaran).
}

investigations on the mechanical properties of HPFRCC and advantages of structures repaired/strengthened by HPFRCC have been carried out [3-10].

Engineered Cementitious Composite (ECC) is a special class of the new generation HPFRCC featuring high ductility with relatively low fiber content. Tensile strain capacity at a range of $3-5 \%$ has been demonstrated in ECC materials using polyvinyl alcohol (PVA) fibers with fiber volume fraction no greater than $2 \%$ [8-10]. Unlike ordinary concrete materials, ECC strain hardens after first cracking like a ductile metal and demonstrates approximately 300-500 times more tensile strain capacity than normal and fiber-reinforced concrete. Even at large imposed deformations under tensile loading, crack widths of ECC remain small, at less than $100 \mu \mathrm{m}$ [11]. High fracture toughness and multiple cracks with tight crack width make ECC an ideal material to improve 
serviceability and durability of infrastructures. In recent years, the field application of ECCs has increased. The material has been successfully applied to dam repair, bridge deck overlays, coupling beams in high-rise buildings, and other structural elements and systems $[2,12,13]$.

During the design of ECC, the criteria of micromechanical design theory, which is a technique to tailor the composite based on the understanding of the mechanical interactions between the matrix, fiber, and interface phases under load, has been considered [8]. In order to obtain desired high ductility, fiber should be uniformly distributed throughout the ECC's matrix, however, in some cases, because of the lack of perfect fiber dispersion or inhomogeneous distribution of fibers, mechanical properties of ECC tends to degrade as well as introduce undesirable variability into the mechanical properties [14]. Moreover, ingredients with inappropriate characteristics (type, size, and amount) as defined by micromechanical principles and ingredients from different sources and/or processing procedures lead to a change in the fresh and hardened properties of ECC. Thus, these facts restrict the widespread application and usability of this unique composite. So far, in most of the previous ECC researches, mix proportion of ECC kept constant or only the mineral admixture (generally fly ash) to cement ratio was changed, and all other parameters were kept constant $[10,15,16]$. However, it is very well known that the optimal design of the ECC mixture parameters committed to the micromechanical design theory criteria might be a very powerful tool to modify the workability and rheological properties of fresh cementitious mixture and mechanical properties of hardened composites.

The objective of this study is to investigate the effect of basic ECC design parameters such as water-binder (w/b), sand-binder $(\mathrm{s} / \mathrm{b})$, superplasticizer-binder $(\mathrm{SP} / \mathrm{b})$ ratios and maximum aggregate size $\left(D_{\max }\right)$ on the workability, rheological and mechanical properties of ECC and try to find out the optimal ECC mixture design for the maximization of the different performances. For this purpose, a factorial experimental design program was performed by considering the $\mathrm{w} / \mathrm{b}, \mathrm{s} / \mathrm{b}, \mathrm{SP} / \mathrm{b}$ and $D_{\max }$ parameters to carry out their effectiveness on realizing the desired fresh (mini-slump flow and Marsh cone flow time, yield stress and plastic viscosity) and mechanical (crack size and density, mid-span beam deflection capacity, flexural and compressive strengths) properties. Then, the influences of each parameter and their interactions were characterized and statistically analyzed. After that, regression models were developed for the tested ECC parameters as function of $w / b$, $\mathrm{s} / \mathrm{b}, \mathrm{SP} / \mathrm{b}$ and $D_{\max }$. Finally, for the desired workability, rheological and mechanical characteristics, best possible ECC mixture under the constraints of this research was defined to meet the multiple objectives at the same time.

\section{Experimental studies}

\subsection{Studied parameters and mixture proportions}

As mentioned earlier, the design of ECC has been performed based on the micro-mechanical design theory constraining the alteration of ingredients' type and amount. Water-binder ratio, fiber (type, dimension and content) and sand-binder ratio can be considered as mixture constraints of ECC design. In order to get the desired tensile ductility, crack size and density after mechanical loading, ECC must be produced in accordance with the micromechanical design theory and production process. Otherwise, improper design and processing may lead to non-uniform fiber dispersion, inappropriate flaw size and distribution, or other microstructures not conducive to multiple cracking [14]. Suitable processing control is necessary to realize composite materials with expected optimal properties. In this study, the effect of four parameters, which are $\mathrm{w} / \mathrm{b}, \mathrm{s} / \mathrm{b}, \mathrm{SP} / \mathrm{b}$ and $D_{\max }$, were studied by committed to the micromechanical design theory. Before deciding the range of parameters given below, a number of trial mixtures varying in $\mathrm{w} / \mathrm{b}, \mathrm{s} / \mathrm{b}, \mathrm{SP} / \mathrm{b}$ and $D_{\max }$ are proportioned and cast to meet a sufficient fresh and hardened properties for ECC [14]. All of these parameters were constrained or loosely constrained in ECC mixture design so the decided ranges of studied parameters as a result of trial mixtures were kept in a narrow interval. It is aimed to find out the effect of some fine tuning on the important design parameters governing the fresh, rheological and mechanical properties of ECC in the present study:

- $\mathrm{w} / \mathrm{b}$ ratio (by mass), often used to adjust the workability of cementitious materials and it was studied as 0.27 (ratio for standard ECC - M45 design [10]) and 0.30;

- SP/b (\%), reflecting the amount of superplasticizer (SP), a commonly used admixture to enhance the fluidity of cementitious materials; and studied as the percent of $(0.200 \%$, $0.225 \%, 0.250 \%, 0.275 \%, 0.300 \%$ and $0.325 \%$ ) binder content;

- s/b (by mass), defined as the ratio of the amount of sand to total binder (Portland cement + fly ash), is used to find out the effect of sand content increment and it was studied as 0.36 (ratio for standard ECC - M45 design [10]) and 0.45;

- $D_{\max }$, is used to clarify how the change of maximum aggregate size $\left(D_{\max }\right)$ will affect the properties of ECC. Two different sizes of $D_{\max }$ were studied, $400 \mu \mathrm{m}$ and $1000 \mu \mathrm{m}$. In standard ECC - M45 design, $D_{\max }$ is $200 \mu \mathrm{m}$ [10].

The increase in aggregate size and amount leads to an increase in the matrix toughness, which deteriorates the composite toughness in accordance with the micromechanical-based design calculations. Recently, fly ash (FA) has become what some consider a necessary component of ECC $[10,15,16]$. Increasing the FA content in ECC mixtures tends to improve the ductility of composites. The improvement in the tensile strain with the increase in the FA content can be attributed to the fact that the increase in the FA content tends to reduce the fiber/matrix interface chemical bond and matrix toughness, while increasing the interface frictional bond, in favor of attaining high tensile strain capacity [10]. In this study, in each mixture, about $70 \%$ of the Portland cement (FA/Portland cement ratio of 2.2 , by mass) was replaced by fly ash in the production of ECC mixtures to compensate the increase in matrix fracture toughness caused by the increase in aggregate size and amount.

The four parameters listed above are chosen as the parameters of experimental design of this research and totally 36 ECC mixtures were developed and tested. Table 1 gives the details of the ECC mixtures.

\subsection{Materials}

CEM I 42.5 R Portland cement (PC), Class F fly ash (FA) conforming to ASTM C 618 requirements with a lime content of $1.64 \%$, fine quartz with two different maximum aggregate size, polycarboxylate ether type high range water reducing admixture (HRWR) and polyvinyl alcohol (PVA) fiber were used in the production of ECC mixtures. Chemical composition and physical properties of PC and FA are presented in Table 2. The particle size distributions of PC and FA obtained by a laser scattering technique, is given in Fig. 1. So far, ECC has been successfully produced with an average grain size of about $110 \mu \mathrm{m}$ silica sand [8] to obtain high ductility, tight crack width and high crack density. However, in order to improve the usability and applicability of ECC, it is very important to produce ECC with aggregates having more common sizes. For this purpose, in this research, ECC was produced by using the fine quartz with two maximum aggregate sizes $\left(D_{\max }\right)$ of $400 \mu \mathrm{m}$ and $1000 \mu \mathrm{m}$. Water absorption capacity and specific gravity of quartz 
Table 1

ECC mixture proportions.

\begin{tabular}{|c|c|c|c|c|c|c|c|c|c|c|}
\hline Mix ID & $\mathrm{w} / \mathrm{b}$ & $\mathrm{s} / \mathrm{b}$ & $\mathrm{SP} / \mathrm{b}(\%)$ & $D_{\max }(\mu \mathrm{m})$ & $\mathrm{PC}\left(\mathrm{kg} / \mathrm{m}^{3}\right)$ & $\mathrm{FA}\left(\mathrm{kg} / \mathrm{m}^{3}\right)$ & Water $\left(\mathrm{kg} / \mathrm{m}^{3}\right)$ & PVA $\left(\mathrm{kg} / \mathrm{m}^{3}\right)$ & Sand $\left(\mathrm{kg} / \mathrm{m}^{3}\right)$ & $\mathrm{SP}\left(\mathrm{kg} / \mathrm{m}^{3}\right)$ \\
\hline M1 & 0.27 & 0.36 & 0.200 & 400 & 381 & 838 & 329 & 26 & 443 & 2.43 \\
\hline M2 & 0.27 & 0.36 & 0.225 & 400 & 381 & 838 & 329 & 26 & 443 & 2.74 \\
\hline M3 & 0.27 & 0.36 & 0.250 & 400 & 381 & 837 & 329 & 26 & 443 & 3.05 \\
\hline M4 & 0.27 & 0.36 & 0.275 & 400 & 381 & 837 & 329 & 26 & 442 & 3.35 \\
\hline M5 & 0.27 & 0.36 & 0.300 & 400 & 381 & 837 & 329 & 26 & 442 & 3.66 \\
\hline M6 & 0.27 & 0.36 & 0.325 & 400 & 381 & 837 & 329 & 26 & 442 & 3.95 \\
\hline M7 & 0.27 & 0.45 & 0.200 & 400 & 367 & 806 & 317 & 26 & 524 & 2.34 \\
\hline M8 & 0.27 & 0.45 & 0.225 & 400 & 367 & 806 & 317 & 26 & 524 & 2.64 \\
\hline M9 & 0.27 & 0.45 & 0.250 & 400 & 367 & 806 & 317 & 26 & 523 & 2.93 \\
\hline M10 & 0.27 & 0.45 & 0.275 & 400 & 367 & 806 & 317 & 26 & 523 & 3.23 \\
\hline M11 & 0.27 & 0.45 & 0.300 & 400 & 367 & 806 & 316 & 26 & 523 & 3.52 \\
\hline M12 & 0.27 & 0.45 & 0.325 & 400 & 367 & 805 & 316 & 26 & 523 & 3.80 \\
\hline M13 & 0.27 & 0.36 & 0.200 & 1000 & 381 & 838 & 329 & 26 & 443 & 2.43 \\
\hline M14 & 0.27 & 0.36 & 0.225 & 1000 & 381 & 838 & 329 & 26 & 443 & 2.74 \\
\hline M15 & 0.27 & 0.36 & 0.250 & 1000 & 381 & 837 & 329 & 26 & 443 & 3.05 \\
\hline M16 & 0.27 & 0.36 & 0.275 & 1000 & 381 & 837 & 329 & 26 & 442 & 3.35 \\
\hline M17 & 0.27 & 0.36 & 0.300 & 1000 & 381 & 837 & 329 & 26 & 442 & 3.66 \\
\hline M18 & 0.27 & 0.36 & 0.325 & 1000 & 381 & 837 & 329 & 26 & 442 & 3.95 \\
\hline M19 & 0.27 & 0.45 & 0.200 & 1000 & 367 & 806 & 317 & 26 & 524 & 2.34 \\
\hline M20 & 0.27 & 0.45 & 0.225 & 1000 & 367 & 806 & 317 & 26 & 524 & 2.64 \\
\hline M21 & 0.27 & 0.45 & 0.250 & 1000 & 367 & 806 & 317 & 26 & 523 & 2.93 \\
\hline M22 & 0.27 & 0.45 & 0.275 & 1000 & 367 & 806 & 317 & 26 & 523 & 3.23 \\
\hline M23 & 0.27 & 0.45 & 0.300 & 1000 & 367 & 806 & 316 & 26 & 523 & 3.52 \\
\hline M24 & 0.27 & 0.45 & 0.325 & 1000 & 367 & 805 & 316 & 26 & 523 & 3.80 \\
\hline M25 & 0.30 & 0.36 & 0.200 & 400 & 367 & 807 & 353 & 26 & 427 & 2.35 \\
\hline M26 & 0.30 & 0.36 & 0.225 & 400 & 367 & 807 & 353 & 26 & 427 & 2.64 \\
\hline M27 & 0.30 & 0.36 & 0.250 & 400 & 367 & 807 & 353 & 26 & 427 & 2.94 \\
\hline M28 & 0.30 & 0.36 & 0.275 & 400 & 367 & 807 & 353 & 26 & 427 & 3.23 \\
\hline M29 & 0.30 & 0.36 & 0.300 & 400 & 367 & 807 & 353 & 26 & 427 & 3.53 \\
\hline M30 & 0.30 & 0.36 & 0.325 & 400 & 367 & 807 & 353 & 26 & 427 & 3.81 \\
\hline M31 & 0.30 & 0.45 & 0.200 & 400 & 354 & 778 & 340 & 26 & 506 & 2.26 \\
\hline M32 & 0.30 & 0.45 & 0.225 & 400 & 354 & 778 & 340 & 26 & 506 & 2.55 \\
\hline M33 & 0.30 & 0.45 & 0.250 & 400 & 354 & 778 & 340 & 26 & 506 & 2.83 \\
\hline M34 & 0.30 & 0.45 & 0.275 & 400 & 354 & 778 & 340 & 26 & 506 & 3.12 \\
\hline M35 & 0.30 & 0.45 & 0.300 & 400 & 354 & 778 & 340 & 26 & 506 & 3.40 \\
\hline M36 & 0.30 & 0.45 & 0.325 & 400 & 354 & 778 & 340 & 26 & 506 & 3.67 \\
\hline
\end{tabular}

Table 2

Chemical composition and physical properties of cement and fly ash.

\begin{tabular}{lll}
\hline Chemical composition & PC & FA \\
\hline $\mathrm{CaO}(\%)$ & 61.43 & 1.64 \\
$\mathrm{SiO}_{2}(\%)$ & 20.77 & 56.22 \\
$\mathrm{Al}_{2} \mathrm{O}_{3}(\%)$ & 5.55 & 25.34 \\
$\mathrm{Fe}_{2} \mathrm{O}_{3}(\%)$ & 3.35 & 7.65 \\
$\mathrm{MgO}(\%)$ & 2.49 & 1.8 \\
$\mathrm{SO}(\%)$ & 2.49 & 0.32 \\
$\mathrm{~K}_{2} \mathrm{O}(\%)$ & 0.77 & 1.88 \\
$\mathrm{Na}_{2} \mathrm{O}(\%)$ & 0.19 & 1.13 \\
$\mathrm{Loss}_{\text {on ignition }(\%)}$ & 2.2 & 2.1 \\
$\mathrm{SiO}_{2}+\mathrm{Al}_{2} \mathrm{O}_{3}+\mathrm{Fe}_{2} \mathrm{O}_{3}$ & 29.37 & 89.21 \\
Physical properties $_{\text {Specific gravity }}$ & & \\
Blaine fineness $\left(\mathrm{m}^{2} / \mathrm{kg}\right)$ & 3.06 & 2.31 \\
\hline
\end{tabular}

aggregate used are $0.3 \%$ and 2.60 , respectively. The grain size distribution curves for these aggregates are also presented in Fig. 1.

Li and co-workers suggested using of polyvinyl alcohol (PVA) fiber on the production of ECC based on the composite performance and economic considerations [17]. The dimensions of the PVA fiber are $8 \mathrm{~mm}$ in length and $39 \mu \mathrm{m}$ in diameter. The nominal tensile strength and density of the fiber are $1600 \mathrm{MPa}$ and $1300 \mathrm{~kg} / \mathrm{m}^{3}$, respectively. A fiber content of $2 \%$ by volume was used in the mixture design. These decisions were made through ECC micromechanics material design theory and had been experimentally demonstrated to produce good ECC properties in previous investigations $[17,18]$.

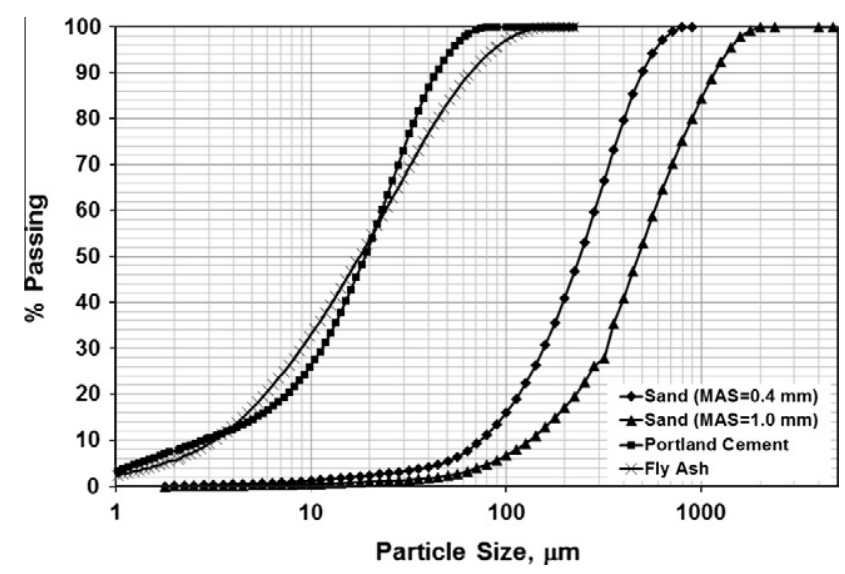

Fig. 1. Particle size distribution of PC, fly ash and quartz sand.

\subsection{Preparation, casting and curing of specimens}

As it is well known, the mixer type, mixing procedure, mixing speed, and temperature may affect the workability and rheological properties of fresh cementitious material $[14,19]$. A mortar mixer with 25-L capacity was used in preparing all ECC mixtures. Solid ingredients except fibers (Portland cement, FA, and aggregate) were first mixed at $100 \mathrm{rpm}$ for a minute. Water and HRWR admixture were then added into the dry mixture and mixed at $150 \mathrm{rpm}$ 
for $1 \mathrm{~min}$ and then at $300 \mathrm{rpm}$ for another $2 \mathrm{~min}$. Such a mixing procedure was shown to produce a consistent and uniform ECC matrices (ECC without PVA fiber) in previous studies [14]. Workability (mini slump flow diameter and Marsh cone flow time) and rheological properties (yield stress and plastic viscosity) measurements were performed on the ECC matrix (w/o PVA fiber). In order to define the compressive strength of ECC matrix at the age of 28 days, six $50-\mathrm{mm}$ cubic specimens were cast. Then, ECC mixtures were produced by using the similar mixing procedure and similar amount of ingredients as ECC matrix and PVA fiber, which was added in last and mixed at $150 \mathrm{rpm}$ for an additional $3 \mathrm{~min}$. Mini-slump flow diameter was also measured on the ECC mixtures and percent variation due to the addition of PVA fiber was determined. From each ECC mixture, six 50-mm cubic specimens were prepared for determining the compressive strength test at the age of 28 days, and six $360 \times 75 \times 50 \mathrm{~mm}$ prisms were prepared for four point bending test at the age of 28 days. All specimens were demolded after $24 \mathrm{~h}$ and cured in sealed plastic bags without external moisture supply at $23 \pm 2{ }^{\circ} \mathrm{C}$ for 7 days. The specimens were then air cured at $50 \pm 5 \%$ relative humidity and $23 \pm 2{ }^{\circ} \mathrm{C}$ until the age of 28 days for testing. This curing procedure is selected since it better represents the real field condition.

\subsection{Test methods for determining workability, rheological and hardened properties}

\subsubsection{Rheological measurements}

Mortar and concrete are generally accepted as a visco-plastic material, which behaves like as a rigid body at low stresses but flows as a viscous fluid at high stresses [19-21]. This behavior follows the rheological model described by Bingham. In that model, Bingham plastic does not exhibit any shear rate (no flow and thus no velocity) until a certain stress (yield stress) is achieved. Once the threshold of the yield stress is overcame, fresh mortar or concrete stars to flow and shear stress increases linearly with an increase in strain rate as defined by plastic viscosity. The plastic viscosity is defined as resistance to flow, once the yield stress is overcome [22]. Therefore, to fully describe the rheological properties of fresh ECC matrix by the Bingham model, two parameters, namely, plastic viscosity and yield stress, are necessary [14].

Rheological parameters of ECC matrix (plastic viscosity and yield stress) were measured using a rotational viscometer with a smooth-walled concentric cylinder (Brookfield DV-II+Pro) at $23 \pm 2{ }^{\circ} \mathrm{C}$. Viscosity of the ECC was measured at different rotational speeds (Fig. 2). The measurements were realized at the rotational speeds ranging from 0 to $100 \mathrm{rpm}$, which corresponds to $34 \mathrm{~s}^{-1}$ shear rate. Then, the rotational speed decreased gradually from 100 to $0 \mathrm{rpm}$. The flow curve was recorded for both the ascending and descending legs of the shear rate-shear stress. Specimens were subjected to shearing for $20 \mathrm{~s}$ for each shear rate $\left(34 \mathrm{~s}^{-1}, 17 \mathrm{~s}^{-1}\right.$, $6.80 \mathrm{~s}^{-1}, 3.40 \mathrm{~s}^{-1}, 1.70 \mathrm{~s}^{-1}, 0.85 \mathrm{~s}^{-1}, 0.34 \mathrm{~s}^{-1}$ and $0.17 \mathrm{~s}^{-1}$ ) and then shear stresses were measured at each shear rate. Shear rate vs. shear stress curves were drawn, and plastic viscosity (slope of descending leg) and yield stress (the point that the descending line of the curve intersects shear stress axis) were calculated by assuming Bingham behavior for each ECC mixture.

The results of rheological measurements often vary very large due to the influence of many factors. Therefore, in this study, rheological measurements were performed under controlled laboratory conditions. Laboratory room temperature was kept constant by an air conditioner and relative humidity was checked before each test. The water was taken from a storage tank to eliminate the variations in tap water temperature. Exactly the same procedure was used in the preparation of each mixture and their testing. Moreover, all tests were performed by the same operator. To minimize the effect of all possible variations, the tests were repeated twice and the average of the results was considered for each mixture. The results of rheological measurements indicate that the tests were repetitive.

\subsubsection{Mini-slump and Marsh cone tests}

As stated earlier, the flow of ECC matrix (i.e. the rheology) following a Bingham fluid behavior can fully be described by two parameters (plastic viscosity and yield stress) determined from rheology tests. On the other hand, a workability test can only indicate only one characteristics of the flow. For example, previous studies show that mini-slump flow can give an idea about the yield stress and Marsh cone flow time can indicate viscosity [14,19]. Therefore, more than one workability test is necessary to estimate the flow behavior of ECC matrix. Moreover, these tests still cannot provide results in basic units. Although workability tests are far from the full description of the flow characteristics, they can be an alternative to rheology tests due to the relatively low cost of the test equipments, easiness of the test procedures and applicability in site conditions. Therefore, workability tests were also performed in this study to enable the practitioners to evaluate the flow of ECC matrix in terms of workability tests. Another difference between rheology and workability tests is that the latter can also help the inspection of the stability of the matrix. Rheological parameters can only be used if the matrix remains stable during the tests.

The workability of fresh ECC matrix was evaluated by measuring the mini-slump flow deformation and Marsh cone flow time. In the mini-slump flow spread test, a truncated cone mold with a diameter of $92.08 \mathrm{~mm}$ at the bottom and $43.50 \mathrm{~mm}$ at the top and a height of $75.78 \mathrm{~mm}$ was placed on a smooth plate, filled with mortar, and lifted upward (Fig. 2). The slump flow deformation was defined as the dimension of the spread when the mortar stops flowing [23]. The Marsh cone test was based on measuring the time necessary for the flow of a particular volume of mortar through a flow cone [23]. A plastic funnel with a capacity of $1500 \mathrm{~mL}$ and an internal orifice diameter of $4.56 \mathrm{~mm}$ was used in this study (Fig. 2). The cone was completely filled with ECC matrix and the bottom outlet was then opened, allowing the mortar to flow out. Marsh cone flow time of ECC matrix was the elapsed time $(t)$ in seconds between the opening of the bottom outlet and the time for the flow of $100 \mathrm{~mL}$ of grout. The marsh cone flow time of fresh ECC matrix is compared to that of water, which was $1.76 \mathrm{~s}$. All tests were repeated twice with a new batch and the results indicate that the tests were repetitive. It is worth to note that the fresh ECC matrixes did not show any significant stability problems in the form of segregation, bleeding or sedimentation during testing as observed from visual inspection.

\subsubsection{Mechanical properties}

Mechanical properties were measured at the age of 28 days. The compressive strength of ECC matrix and composites was measured by using $50-\mathrm{mm}$ cubic specimens [24]. To measure the flexural performance of ECC mixture, six prismatic samples having dimensions of $360 \times 75 \times 50 \mathrm{~mm}$ were cast from each produced ECC mixture. Flexural strength under four-point test was performed by using universal testing system [25]. The span length of flexural loading was $304 \mathrm{~mm}$ with a $101 \mathrm{~mm}$ center span length. The loading rate used was $0.005 \mathrm{~mm} / \mathrm{s}$ to simulate a quasi-static loading condition. During the flexural tests, the flexural stress and midspan beam deflection were recorded on a computerized data recording system. A linear variable displacement transducer (LVDT) was fixed on the test set-up to measure the flexural deflection of the specimen. After flexural tests, crack widths on the surface of the specimens were also measured by using a portable microscope. 


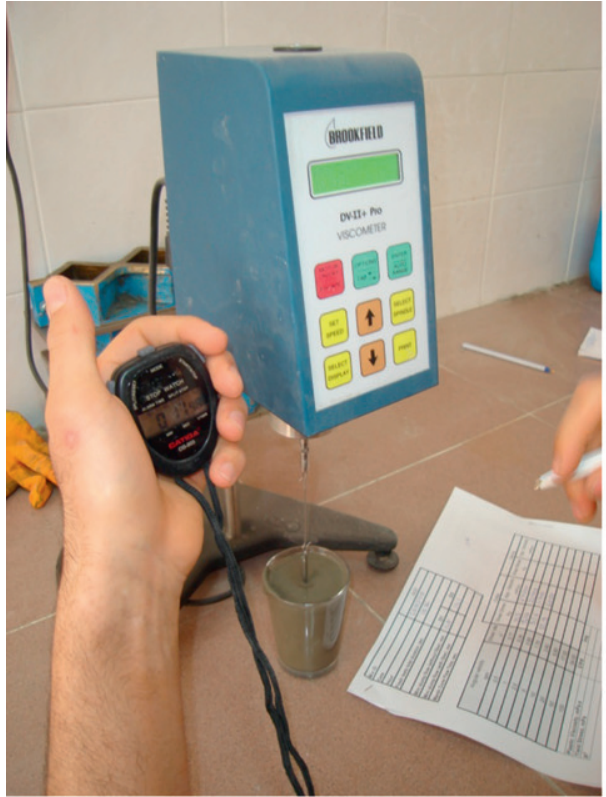

(a)

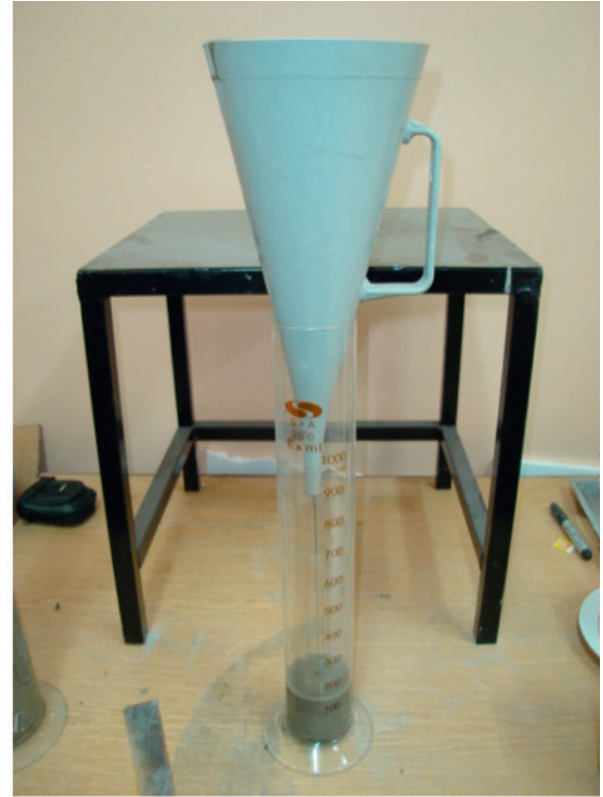

(b)

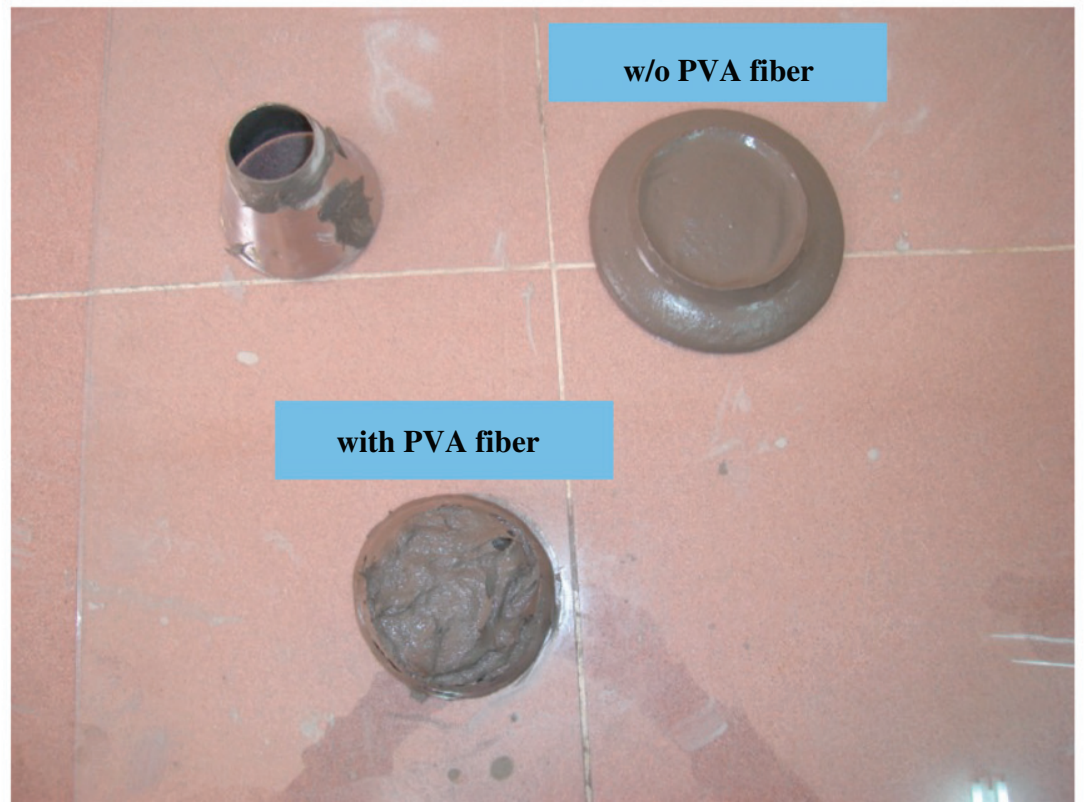

(c)

Fig. 2. Workability and rheology tests for ECC matrix; (a) brookfield DV-II+Pro rotational viscometer; (b) Marsh cone and (c) mini-slump flow cone.

\section{Test results and discussion}

Table 3 presents the rheological parameters (plastic viscosity and yield stress) and workability properties (marsh cone flow time and mini slump flow diameter) of the ECC matrices and mini slump flow diameter of the ECC mixtures. Percent variation in the mini slump flow diameter due to the addition of PVA fibers is also calculated and presented in Table 3. Mid-span beam deflection capacity (at maximum flexural stress) and flexural strength values of ECC mixtures and compressive strength of ECC mixtures and ECC matrices are given in Table 4. Following sections of the paper present the statistical analysis of test results and effect of each parameter, which was studied in the factorial experimental design program. Test results are evaluated and discussed by considering the ANOVA results.

\subsection{Statistical assessments of test results by ANOVA}

The analysis of variance (ANOVA) evaluates whether the independent variables $\left(\mathrm{w} / \mathrm{b}, \mathrm{s} / \mathrm{b}, \mathrm{SP} / \mathrm{b}\right.$ and $\left.D_{\max }\right)$ have an effect on the dependent variables (mini-slump flow diameter, Marsh cone flow time, yield stress, plastic viscosity, mid-span beam deflection capacity, flexural and compressive strengths). It can also be used to identify whether the interactions of independent variables have an effect on the dependent variables. Sometimes, it may be difficult to analyze the effect of different factors on the variation of dependent variables; ANOVA results can be a useful tool to illustrate the effect that the variables have on one another [26,27].

The test results were analyzed to find out the variation in the dependent parameters depending on the independent parameters. A statistical analysis was performed to determine the statistically 
Table 3

Workability and rheological properties.

\begin{tabular}{|c|c|c|c|c|c|c|}
\hline \multirow[t]{3}{*}{ Mix ID } & \multicolumn{4}{|c|}{ ECC matrix (ECC without PVA fibers) } & \multirow{3}{*}{$\begin{array}{l}\text { ECC } \\
\text { Mini slump flow } \\
\text { diameter }(\mathrm{mm})\end{array}$} & \multirow{3}{*}{$\begin{array}{l}\text { Variation in mini } \\
\text { slump flow diameter }(\%)\end{array}$} \\
\hline & \multicolumn{2}{|c|}{ Rheological parameters } & \multirow{2}{*}{$\begin{array}{l}\text { Marsh cone } \\
\text { flow time (s) }\end{array}$} & \multirow{2}{*}{$\begin{array}{l}\text { Mini slump flow } \\
\text { diameter (mm) }\end{array}$} & & \\
\hline & Yield stress $(\mathrm{Pa})^{\mathrm{a}}$ & Plastic viscosity (Pa s) & & & & \\
\hline M1 & 3.376 & 1.640 & - & 150.0 & 104.5 & 30.3 \\
\hline M2 & 3.719 & 1.507 & 181.06 & 173.5 & 121.5 & 30.0 \\
\hline M3 & 3.013 & 1.360 & 178.00 & 227.0 & 126.0 & 44.5 \\
\hline M4 & 1.769 & 1.056 & 88.90 & 299.5 & 156.0 & 47.9 \\
\hline M5 & $\sim 0$ & 0.499 & 55.75 & 352.5 & 165.5 & 53.0 \\
\hline M6 & $\sim 0$ & 0.395 & 40.00 & 404.5 & 188.0 & 53.5 \\
\hline M7 & 4.882 & 1.534 & - & 96.5 & 90.0 & 6.7 \\
\hline M8 & 3.529 & 1.364 & - & 160.5 & 95.0 & 40.8 \\
\hline M9 & 3.627 & 1.454 & 302.65 & 176.0 & 103.0 & 41.5 \\
\hline M10 & 2.758 & 1.377 & 141.01 & 250.5 & 100.5 & 59.9 \\
\hline M11 & 0.267 & 0.803 & 83.20 & 340.0 & 163.0 & 52.1 \\
\hline M12 & 0.474 & 0.468 & 55.06 & 360.0 & 181.5 & 49.6 \\
\hline M13 & 3.338 & 1.640 & - & 158.0 & 103.0 & 34.8 \\
\hline M14 & 2.726 & 1.500 & 123.35 & 216.5 & 128.0 & 40.9 \\
\hline M15 & 1.914 & 1.420 & 73.73 & 276.0 & 145.5 & 47.3 \\
\hline M16 & 1.300 & 1.180 & 91.04 & 286.5 & 135.5 & 52.7 \\
\hline M17 & 0.978 & 0.641 & 58.87 & 326.5 & 156.5 & 52.1 \\
\hline M18 & $\sim 0$ & 0.331 & 48.46 & 378.5 & 189.5 & 49.9 \\
\hline M19 & 6.532 & 1.700 & - & 117.0 & 94.0 & 19.7 \\
\hline M20 & 4.872 & 1.431 & - & 144.5 & 97.0 & 32.9 \\
\hline M21 & 4.188 & 1.655 & - & 174.5 & 114.5 & 34.4 \\
\hline M22 & 4.377 & 1.401 & 272.03 & 191.0 & 102.5 & 46.3 \\
\hline M23 & 2.214 & 1.220 & 126.54 & 264.0 & 115.0 & 56.4 \\
\hline $\mathrm{M} 24$ & 0.527 & 0.683 & 70.53 & 346.0 & 152.5 & 55.9 \\
\hline M25 & 2.222 & 1.140 & 158.48 & 171.5 & 116.0 & 32.4 \\
\hline M26 & 1.930 & 1.037 & 118.53 & 204.5 & 148.5 & 27.4 \\
\hline M27 & 1.944 & 0.922 & 58.86 & 268.5 & 182.5 & 32.0 \\
\hline M28 & 1.005 & 0.582 & 44.72 & 339.0 & 205.0 & 39.5 \\
\hline M29 & 0.535 & 0.417 & 36.11 & 365.0 & 209.5 & 42.6 \\
\hline M30 & $\sim 0$ & 0.252 & 31.47 & 404.0 & 231.5 & 42.7 \\
\hline M31 & 2.725 & 1.164 & - & 133.0 & 98.0 & 26.3 \\
\hline M32 & 2.413 & 1.107 & 362.87 & 161.0 & 102.5 & 36.3 \\
\hline M33 & 2.391 & 1.051 & 126.25 & 205.0 & 122.0 & 40.5 \\
\hline M34 & 2.003 & 0.926 & 75.58 & 269.5 & 159.0 & 41.0 \\
\hline M35 & 0.903 & 0.585 & 54.71 & 338.5 & 187.0 & 44.8 \\
\hline M36 & $\sim 0$ & 0.455 & 52.25 & 360.0 & 203.5 & 43.5 \\
\hline
\end{tabular}

a Negative yield stress values is assumed to zero.

significant ( $p$-level $<0.05$ ) independent parameters and their percentage contributions on the dependent parameters. Statistically significant linear regression models were obtained for each dependent parameter depending on the independent parameters. Statistical analysis was performed and the models that have the $p$-levels less than and equal to 0.05 was accepted as the significant models. ANOVA studies were performed by using a commercial statistical software package (Design-Expert 7.0.3) and results were presented in Table 5.

In ANOVA study, the total sum of squares was calculated, which was partitioned into the sum of squares for individual factors and the sum of the squares for the residual random error. The mean squares of the factors were calculated by dividing their corresponding sum of squares by the associated degrees of freedom. Then, the effect of individual factors was evaluated by testing the hypothesis of equality of variances, which is the test of a null hypothesis or simply the significance test at a particular probability level. For this, the ratio of mean squares of factors to the mean squares of the residual error, i.e. F-statistic, was calculated and compared to the tabulated $F$-values related to Fisher distribution. The $F$-values related to Fisher distribution depend on the number of degrees of freedom of the individual factors, number of degrees of freedom of the residual error and the probability level $[26,28]$. Degree of contribution ( $\rho \%)$ of each significant factor was also obtained to determine the level of its statistical importance in the model. The degree of contribution $(\rho \%)$ of each significant factor was determined according to the computed value of $F$ distribution. After computing the $F$-value of each factor, the ratio of value of each factor to the total value of computed $F$ distribution gave us the degree of contribution of each significant factor. The column under $\rho \%$ in Table 5 provides an idea of the degree of contribution of the independent parameters to the measured dependent parameter (test results). If the $\rho \%$ is high, the contribution of the factors to that particular response is greater. Likewise, the lower the $\rho \%$, the lower the contribution of the factors on the dependent parameter (test results) [29].

\subsubsection{Mini-slump flow diameter}

Mini-slump flow diameter test was used to evaluate the workability of ECC matrix (ECC without PVA fibers) and ECC (with PVA fibers). As seen in Table 3, mini slump flow diameter of the both ECC matrix and ECC increases with the increase of SP/b content irrespective of the $\mathrm{w} / \mathrm{b}, \mathrm{s} / \mathrm{b}$ and $D_{\max }$ design parameters. Gradual increase in mini slump flow diameter with the increase of $\mathrm{SP} / \mathrm{b}$ ratio suggests that neither ECC matrix nor the ECC mixtures did reach to "saturation point" of the used chemical admixtures, no instability and bleeding problem was observed. The saturation point is defined as the superplasticizer dosage beyond which the slump flow diameter and time do not decrease appreciably. As also seen in Table $5, \mathrm{w} / \mathrm{b}, \mathrm{s} / \mathrm{b}$ and SP/b are the significant parameters on the mini-slump flow diameter of the both ECC and ECC matrix. However, SP/b appears to be the most affecting parameter, and its per- 
Table 4

Mechanical properties.

\begin{tabular}{|c|c|c|c|c|}
\hline \multirow{2}{*}{$\begin{array}{l}\text { Mix } \\
\text { ID }\end{array}$} & \multirow{2}{*}{$\begin{array}{l}\text { Mid-span } \\
\text { deflection } \\
\text { at max flexural } \\
\text { load (mm) }\end{array}$} & \multirow{2}{*}{$\begin{array}{l}\text { Flexural } \\
\text { strength } \\
(\mathrm{MPa})\end{array}$} & \multicolumn{2}{|c|}{ Compressive strength (MPa) } \\
\hline & & & $\begin{array}{l}\text { ECC matrix } \\
\text { (w/o PVA } \\
\text { fibers) }\end{array}$ & $\begin{array}{l}\text { ECC (with } \\
\text { PVA } \\
\text { fibers) }\end{array}$ \\
\hline M1 & 4.25 & 10.29 & 49.64 & 51.25 \\
\hline M2 & 5.34 & 10.62 & 50.18 & 50.90 \\
\hline M3 & 6.32 & 10.92 & 51.71 & 53.16 \\
\hline M4 & 5.87 & 11.03 & 47.47 & 54.16 \\
\hline M5 & 5.64 & 10.93 & 47.10 & 54.39 \\
\hline M6 & 5.50 & 10.63 & 46.57 & 54.63 \\
\hline M7 & 3.94 & 10.11 & 44.14 & 46.50 \\
\hline M8 & 4.68 & 10.84 & 48.94 & 51.44 \\
\hline M9 & 5.36 & 11.42 & 44.99 & 47.46 \\
\hline M10 & 5.31 & 10.95 & 49.21 & 51.70 \\
\hline M11 & 5.13 & 10.88 & 45.98 & 46.81 \\
\hline M12 & 5.06 & 10.51 & 51.26 & 56.89 \\
\hline M13 & 3.41 & 9.59 & 44.29 & 48.16 \\
\hline M14 & 3.74 & 9.76 & 46.82 & 46.78 \\
\hline M15 & 4.83 & 9.67 & 47.06 & 47.79 \\
\hline M16 & 4.35 & 10.07 & 46.35 & 47.39 \\
\hline M17 & 4.40 & 9.52 & 51.81 & 55.27 \\
\hline M18 & 4.19 & 9.97 & 51.25 & 55.72 \\
\hline M19 & 2.73 & 9.52 & 46.51 & 45.10 \\
\hline M20 & 3.18 & 9.44 & 43.27 & 46.11 \\
\hline M21 & 3.52 & 9.76 & 47.95 & 46.25 \\
\hline M22 & 4.02 & 9.41 & 45.98 & 48.56 \\
\hline M23 & 3.98 & 9.77 & 51.85 & 51.89 \\
\hline M24 & 3.91 & 9.13 & 48.89 & 50.05 \\
\hline M25 & 5.07 & 7.83 & 41.85 & 39.35 \\
\hline M26 & 6.08 & 8.31 & 42.09 & 40.76 \\
\hline M27 & 6.17 & 8.77 & 41.96 & 42.93 \\
\hline M28 & 5.70 & 8.53 & 41.89 & 43.19 \\
\hline M29 & 5.05 & 8.22 & 44.37 & 41.64 \\
\hline M30 & 4.88 & 8.63 & 40.75 & 44.95 \\
\hline M31 & 4.56 & 7.77 & 38.30 & 39.14 \\
\hline M32 & 4.41 & 7.77 & 38.22 & 38.47 \\
\hline M33 & 4.96 & 8.10 & 40.19 & 41.60 \\
\hline M34 & 4.38 & 8.33 & 39.74 & 44.21 \\
\hline M35 & 4.26 & 8.62 & 42.48 & 42.14 \\
\hline M36 & 3.90 & 8.55 & 38.68 & 40.58 \\
\hline
\end{tabular}

cent contribution on the mini-slump flow diameter increase was around $90 \%$. Superplasticizers are surface active agents, and their usage modifies the surface charges on the cement particles and thus make them disperse [30]. Moreover, the superplasticizer used in this research has also steric effect, which disperses the cement particles by its long polymer chains. Contrary to the expectations, effect of $\mathrm{w} / \mathrm{b}$ parameter on the variation of mini slump flow values is at very low level and its percent contribution according to the ANOVA results was around $1.6 \%$. This may be due to the relatively narrow range ( 0.27 and 0.30 ) of $\mathrm{w} / \mathrm{b}$ parameter. ANOVA results also show that increasing the $\mathrm{s} / \mathrm{b}$ ratio from 0.36 to 0.45 influenced the mini-slump flow diameter around $8.4 \%$. As also seen in Table 3 and as expected, with the addition of PVA fiber to the ECC matrix, mini slump flow diameter decreased remarkably. Therefore, the addition of PVA fiber significantly influences the workability properties and rheological parameters fresh ECC mixture.

\subsubsection{Marsh cone test}

The Marsh cone test is a workability test used for specification and quality control of cement pastes and grouts [31]. In the present study, it is used to measure flow time of fresh ECC matrix. This measured flow time is linked with the fluidity of the ECC matrix. The longer the flow time, the lower the fluidity of the ECC matrix. Marsh cone flow test results and their analysis of variance outcome are presented in Tables 3 and 5, respectively. As seen in Table 3, some ECC matrices do not have the Marsh cone flow time due to their low consistency, and increment in SP/b content and w/b ratio eliminated the low consistency and ECC matrix started to flow due to its own weight and gravity force. Moreover, augmentation in $\mathrm{s} / \mathrm{b}$ ratio negatively affects the fluidity of the ECC matrix and increased number of mixtures, which do not have the measured Marsh cone flow time. Consistent with the ANOVA results, fluidity of the ECC matrix soared with increase of $\mathrm{SP} / \mathrm{b}$ ratio, which exhibited the greatest effect of $74.6 \%$ on the fluidity time of ECC matrix. As in mini-slump flow test results, $\mathrm{SP} / \mathrm{b}$ parameter was followed by the $\mathrm{s} / \mathrm{b}$ and $\mathrm{w} / \mathrm{b}$ parameters with the contributions of $16.9 \%$ and $8.5 \%$, respectively. It can be observed that Marsh cone flow times increase with the decrease in $\mathrm{w} / \mathrm{b}$, as expected. However, as a result of the narrow range in experimental program, its contribution on flow time by ANOVA was appeared limited to $8.5 \%$. As also in mini-slump flow diameter, increase of maximum aggregate size from $400 \mu \mathrm{m}$ to $1000 \mu \mathrm{m}$ did not significantly affect the fluidity time of ECC matrix. ANOVA results also confirmed mentioned results, and $D_{\max }$ parameter appeared as insignificant.

\subsubsection{Yield stress}

Yield stress is the shear stress required by a viscoelastic material for initiating a plastic deformation. It is the maximum shear stress under which the material is at rest but beyond which the material will start to flow or deform [32]. Lower yield stress of the ECC matrix requires less stress to initiate flow (lower yield stress generally corresponds to higher slump flow). The ECC matrix material stops flowing when the weight of the matrix is lower than the yield stress [14]. Yield stress values of the produced ECC matrices are presented in Table 3 and Fig. 3. As the test results are evaluated, it can be easily seen that some ECC matrices have negative yield stress values due to the possible measurement artifacts. Negative yield stress might occur due to the deviations from the Bingham model and resulting in a non-linear relationship between shear stress and shear rate [33-35]. However, in general, as seen in Fig. 3, yield stress dropped off remarkably with the increase in $\mathrm{SP} / \mathrm{b}$ and $\mathrm{w} / \mathrm{b}$ ratio irrespective of $\mathrm{s} / \mathrm{b}$ and $D_{\max }$ parameters. This is mostly due to the dispersing action of the SP. In dispersing action, the polycarboxylate ether-based SP hinders the flocculation of cement particles and disperses them more evenly due to steric repulsion, hence enhancing the flowing ability of the binder pastes through reduced interparticle friction and greater free water content [36], therefore, lower yield stress of fresh ECC mixture [14]. Increase in $\mathrm{s} / \mathrm{b}$ ratio from 0.36 to 0.45 increased the yield stress values of the ECC matrix for both $\mathrm{w} / \mathrm{b}$ ratios; most probably due to the higher degree of friction and collision of solid particles, which increases the matrix shear stress and viscosity [37]. Moreover, alteration of maximum aggregate size from $400 \mu \mathrm{m}$ to $1000 \mu \mathrm{m}$ slightly affected the yield stress values of the ECC matrix. The smaller aggregate size results in higher yield stress. This agrees with the common finding that a decrease in maximum size of aggregate generally increases the water demand of the concrete $[37,38]$. As known, with the increase in maximum aggregate size, surface area per unit volume, which has to be dampened by mixing water, will be decreased. However, this conclusion has a contrast with the finding of ANOVA study; $D_{\max }$ parameter is not a statistically significant on the yield value of ECC matrix. ANOVA results also showed that three parameters $-\mathrm{w} / \mathrm{b}, \mathrm{s} / \mathrm{b}$ and SP/b - are statistically significant on the yield stress values of the ECC matrix with the contributions of $10.5 \%, 12.7 \%$, and $76.8 \%$, respectively.

\subsubsection{Plastic viscosity}

Plastic viscosity controls the flow of the ECC matrix when the matrix beaten the yield stress value. In case of self-compactability of matrix, due to the addition of superplasticizers, it is known that the yield stress is much lower when compared to conventional concrete [35]. In that situation, the plastic viscosity must be high 
Table 5

Statistical evaluation of test results by ANOVA.

\begin{tabular}{|c|c|c|c|c|c|c|c|c|c|c|}
\hline Dependent parameters & Independent parameters & Regression model & $R$ & $\mathrm{DF}$ & SSS & MS & $F$-value & $P$-value & $S$ & $\rho \%$ \\
\hline Mini slump flow diameter & $\begin{array}{l}\text { Constant } \\
\mathrm{w} / \mathrm{b} \\
\mathrm{s} / \mathrm{b} \\
\mathrm{SP} / \mathrm{b} \\
D_{\max } \\
\text { Error }\end{array}$ & $\begin{array}{l}-25.9 \\
790.9 \\
-1191.1 \\
1947.1 \\
- \\
-\end{array}$ & 0.978 & $\begin{array}{l}- \\
1 \\
1 \\
1 \\
- \\
32\end{array}$ & $\begin{array}{l}- \\
4505 \\
23205 \\
248784 \\
- \\
12498\end{array}$ & $\begin{array}{l}- \\
4506 \\
23205 \\
248784 \\
- \\
386\end{array}$ & $\begin{array}{l}- \\
11.5 \\
59.4 \\
636.9 \\
- \\
-\end{array}$ & $\begin{array}{l}- \\
<0.0001 \\
<0.0001 \\
<0.0001 \\
- \\
-\end{array}$ & $\begin{array}{l}- \\
\mathrm{Y} \\
\mathrm{Y} \\
\mathrm{Y} \\
\mathrm{N} \\
-\end{array}$ & $\begin{array}{l}- \\
1.6 \\
8.4 \\
90.0 \\
- \\
-\end{array}$ \\
\hline Marsh cone flow time & $\begin{array}{l}\text { Constant } \\
\mathrm{w} / \mathrm{b} \\
\mathrm{s} / \mathrm{b} \\
\mathrm{SP} / \mathrm{b} \\
D_{\max } \\
\text { Error }\end{array}$ & $\begin{array}{l}912.2 \\
-3820.2 \\
3564.6 \\
-3741.3 \\
- \\
-\end{array}$ & 0.856 & $\begin{array}{l}1 \\
1 \\
1 \\
- \\
32\end{array}$ & $\begin{array}{l}105074 \\
207837 \\
918558 \\
- \\
444750\end{array}$ & $\begin{array}{l}105074 \\
207837 \\
918558 \\
- \\
13898\end{array}$ & $\begin{array}{l}7.6 \\
15.0 \\
66.1 \\
- \\
-\end{array}$ & $\begin{array}{l}0.0473 \\
0.0006 \\
<0.0001 \\
- \\
-\end{array}$ & $\begin{array}{l}\mathrm{Y} \\
\mathrm{Y} \\
\mathrm{Y} \\
\mathrm{N} \\
-\end{array}$ & $\begin{array}{l}8.5 \\
16.9 \\
74.6 \\
- \\
-\end{array}$ \\
\hline Yield stress & $\begin{array}{l}\text { Constant } \\
\mathrm{w} / \mathrm{b} \\
\mathrm{s} / \mathrm{b} \\
\mathrm{SP} / \mathrm{b} \\
D_{\max } \\
\text { Error }\end{array}$ & $\begin{array}{l}10.2 \\
-33.9 \\
24.9 \\
-30.5 \\
-\end{array}$ & 0.901 & $\begin{array}{l}- \\
1 \\
1 \\
1 \\
- \\
32\end{array}$ & $\begin{array}{l}- \\
8.3 \\
10.1 \\
60.929 \\
- \\
18.2\end{array}$ & $\begin{array}{l}- \\
8.3 \\
10.1 \\
60.9 \\
- \\
0.5\end{array}$ & $\begin{array}{l}- \\
14.6 \\
17 . .8 \\
107.2 \\
- \\
-\end{array}$ & $\begin{array}{l}- \\
0.0006 \\
0.0002 \\
<0.0001 \\
- \\
-\end{array}$ & $\begin{array}{l}- \\
\mathrm{Y} \\
\mathrm{Y} \\
\mathrm{Y} \\
\mathrm{N} \\
-\end{array}$ & $\begin{array}{l}- \\
10.5 \\
12.7 \\
76.8 \\
- \\
-\end{array}$ \\
\hline Plastic viscosity & $\begin{array}{l}\text { Constant } \\
\mathrm{w} / \mathrm{b} \\
\mathrm{s} / \mathrm{b} \\
\mathrm{SP} / \mathrm{b} \\
D_{\max } \\
\text { Error }\end{array}$ & $\begin{array}{l}5.3 \\
-12.5 \\
3.7 \\
-8.4 \\
0.95\end{array}$ & 0.927 & $\begin{array}{l}- \\
1 \\
1 \\
1 \\
\\
32\end{array}$ & $\begin{array}{l}- \\
1.1 \\
0.2 \\
4.6\end{array}$ & $\begin{array}{l}- \\
1.1 \\
0.2 \\
4.6 \\
0.03\end{array}$ & $\begin{array}{l}- \\
37.6 \\
7.6 \\
153.6 \\
-\end{array}$ & $\begin{array}{l}- \\
<0.0001 \\
0.0095 \\
<0.0001 \\
-\end{array}$ & $\begin{array}{l}- \\
\mathrm{Y} \\
\mathrm{Y} \\
\mathrm{Y} \\
\mathrm{N}\end{array}$ & $\begin{array}{l}- \\
18.9 \\
3.8 \\
77.2\end{array}$ \\
\hline Mid-span deflection at maximum flexural stress & $\begin{array}{l}\text { Constant } \\
\text { w/b } \\
\mathrm{s} / \mathrm{b} \\
\mathrm{SP} / \mathrm{b} \\
D_{\max } \\
\text { Error }\end{array}$ & $\begin{array}{l}16.7 \\
- \\
-17.6 \\
- \\
-0.012 \\
-\end{array}$ & 0.800 & $\begin{array}{l}- \\
1 \\
1 \\
33\end{array}$ & $\begin{array}{l}- \\
5.1 \\
11.9 \\
9.5\end{array}$ & $\begin{array}{l}- \\
5.1 \\
10.9 \\
0.3\end{array}$ & $\begin{array}{l}- \\
17.5 \\
41.3 \\
-\end{array}$ & $\begin{array}{l}- \\
0.0002 \\
<0.0001 \\
-\end{array}$ & $\begin{array}{l}- \\
\mathrm{N} \\
\mathrm{Y} \\
\mathrm{N} \\
\mathrm{Y} \\
-\end{array}$ & $\begin{array}{l}- \\
- \\
29.8 \\
- \\
70.2 \\
-\end{array}$ \\
\hline Flexural strength & $\begin{array}{l}\text { Constant } \\
\text { w/b } \\
\text { s/b } \\
\mathrm{SP} / \mathrm{b} \\
D_{\max } \\
\text { Error }\end{array}$ & $\begin{array}{l}36.8 \\
-82.5 \\
- \\
2.8 \\
-0.011 \\
-\end{array}$ & 0.986 & $\begin{array}{l}- \\
1 \\
1 \\
1 \\
32\end{array}$ & $\begin{array}{l}- \\
36.8 \\
- \\
0.5 \\
7.6 \\
2.9\end{array}$ & $\begin{array}{l}- \\
36.8 \\
- \\
0.5 \\
7.6 \\
0.1\end{array}$ & $\begin{array}{l}- \\
400.3 \\
- \\
5.7 \\
82.9 \\
-\end{array}$ & $\begin{array}{l}- \\
<0.0001 \\
0.1893 \\
0.0217 \\
<0.0001 \\
-\end{array}$ & $\begin{array}{l}- \\
\mathrm{Y} \\
\mathrm{N} \\
\mathrm{Y} \\
\mathrm{Y} \\
-\end{array}$ & $\begin{array}{l}- \\
81.9 \\
- \\
1.2 \\
17.0 \\
-\end{array}$ \\
\hline Compressive strength & $\begin{array}{l}\text { Constant } \\
\mathrm{w} / \mathrm{b} \\
\mathrm{s} / \mathrm{b} \\
\mathrm{SP} / \mathrm{b} \\
D_{\max } \\
\text { Error }\end{array}$ & $\begin{array}{l}122.9 \\
-240.8 \\
-34.6 \\
19.5\end{array}$ & 0.864 & $\begin{array}{l}- \\
1 \\
1 \\
1 \\
- \\
32\end{array}$ & $\begin{array}{l}- \\
392.8 \\
19.6 \\
24.9 \\
- \\
148.3\end{array}$ & $\begin{array}{l}- \\
313.0 \\
19.6 \\
24.9 \\
- \\
4.6\end{array}$ & $\begin{array}{l}- \\
84.8 \\
4.2 \\
5.4 \\
- \\
-\end{array}$ & $\begin{array}{l}- \\
<0.0001 \\
0.0478 \\
0.0269 \\
- \\
-\end{array}$ & $\begin{array}{l}- \\
\mathrm{Y} \\
\mathrm{Y} \\
\mathrm{Y} \\
\mathrm{N} \\
-\end{array}$ & $\begin{array}{l}- \\
89.8 \\
4.5 \\
5.7 \\
- \\
-\end{array}$ \\
\hline
\end{tabular}

${ }^{*} R$ : correlation coefficient; DF: degree of freedom; SS: sum of squares; MS: Mean square; S: Significancy.

enough to maintain the stability of the matrix. For the uniform distribution of PVA fibers in ECC, viscosity of the matrix became very important to obtain the desired fiber bridging efficiency of PVA fiber. Plastic viscosity test results and their variance analysis are given in Tables 3 and 5, respectively. Fig. 4 also illustrates the variation of plastic viscosity depending on the $w / b, s / b, S P / b$ and $D_{\max }$ parameters. As shown in Table 5 , the plastic viscosity is influenced by, in decreasing significance order, $\mathrm{SP} / \mathrm{b}, \mathrm{w} / \mathrm{b}$ and $\mathrm{s} / \mathrm{b}$ parameters. The SP/b had the greatest effect on the plastic viscosity (77.2\%). The increase in the ratio of $\mathrm{w} / \mathrm{b}$ had about five times greater effect than an increase in s/b ratio (18.9\% vs. 3.8\%). However, the increase in SP/b ratio had approximately four times greater influence than the $\mathrm{w} / \mathrm{b}$ ratio on decreasing plastic viscosity of ECC matrix. Influence of SP/b ratio has deserved attention when used with low w/b ratio mixtures. As also seen in Fig. 4, steady increase in SP/ b ratio had considerably impairment in plastic viscosity of ECC matrix regardless of $\mathrm{w} / \mathrm{b}, \mathrm{s} / \mathrm{b}$ and $D_{\max }$ parameters. The repulsive effect, dispersion of particles and low buildup of structure formation might be responsible for the noteworthy effect of SP/b on plastic viscosity of ECC matrix. Regarding the effect of $w / b$ ratio, the friction reduction of surface particle might be considered [39]. The test results also indicate that ECC matrix viscosity increases slightly with an increase in $\mathrm{s} / \mathrm{b}$ ratio, but does not always increase with the augmentation of maximum aggregate size. The plastic viscosity of cement paste, as in the yield stress, mini-slump flow diameter and Marsh cone flow time, is obviously a function of the superplasticizer, water, and quartz sand contents, reflected by the ratios of $\mathrm{SP} / \mathrm{b}, \mathrm{w} / \mathrm{b}$, and $\mathrm{s} / \mathrm{b}$ parameter. Therefore, in order to obtain ECC matrix with desired flowability together with target yield stress and plastic viscosity, regulation of SP/b ratio is crucial.

\subsubsection{Mid-span beam deflection}

Mid-span beam deflection capacity of ECC mixtures, which indicates the material ductility, depends on the $\mathrm{w} / \mathrm{b}, \mathrm{s} / \mathrm{b}, \mathrm{SP} / \mathrm{b}$ and $D_{\max }$ parameters as given Table 4, and the variation of mid-span beam deflection values vs. SP/b ratio are demonstrated for all tested ECC mixtures in Fig. 5. Statistical analysis of the test results is given in Table 5. As shown in both Table 5 and Fig. 5, mid-span beam deflection capacities varied noticeably with the change of $s / b$ and $D_{\text {max }}$ design parameters. Both of these two parameters negatively affect the deflection capacity of the ECC mixtures: Increasing the $\mathrm{s} / \mathrm{b}$ ratio from 0.36 to 0.45 and augmentation of the maximum aggregate size from 400 to $1000 \mu \mathrm{m}$ decreased the mid span beam deflection capacities at the percent contribution of $29.8 \%$ and $70.2 \%$, respectively. Mentioned diminishing effect of both $\mathrm{s} / \mathrm{b}$ and $D_{\text {max }}$ parameters on ductility might be attributed to the corre- 

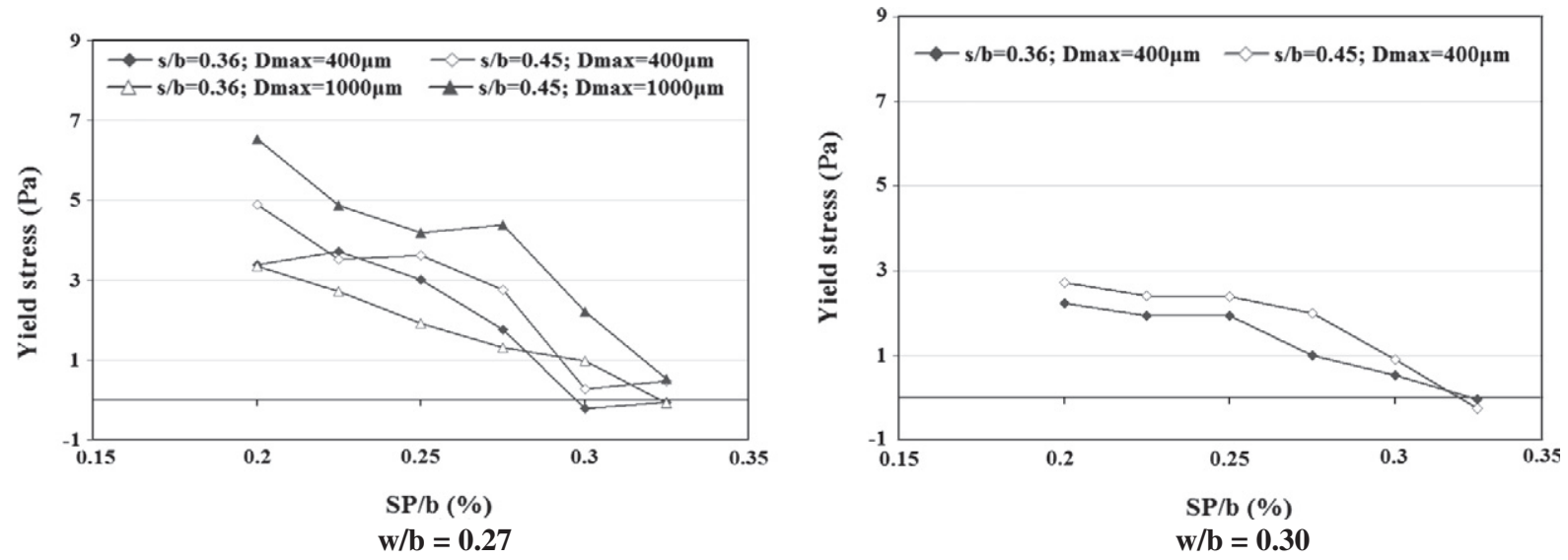

Fig. 3. Variation of yield stress.
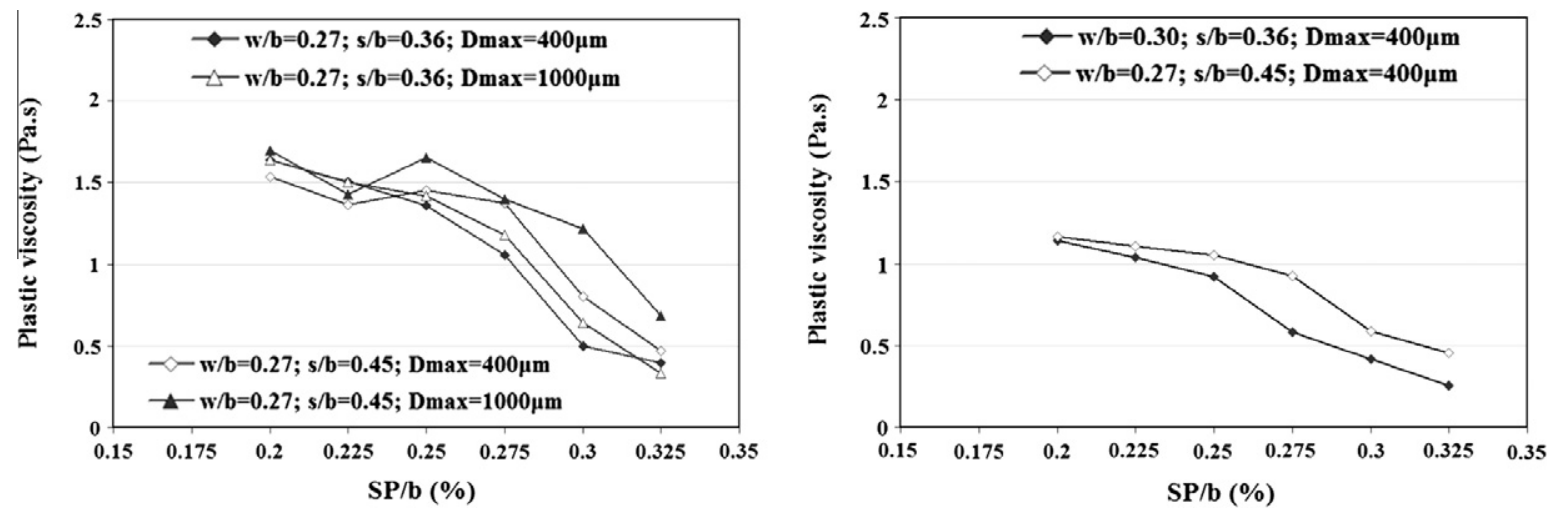

Fig. 4. Variation of plastic viscosity.

sponding damage to the uniform dispersion of fibers. The balling of fibers encouraged by relatively coarser quarts sand prevents sufficient coating of fibers by the matrix, and thus reduces the fiber-to-matrix bonding, which is an important factor influencing ductility [40]. Moreover, for ECC with the higher s/b ratio and higher $D_{\text {max }}$, a higher degree of aggregate interlock is expected, resulting in higher matrix toughness and work-of-fracture during crack propagation. According to the micromechanical model of steady state cracking, which is essential to achieve strain hardening behavior, high matrix fracture toughness reduces the margin to develop multiple microcracking [8]. Despite the statistically insignificancy of the SP/b parameter on the mid-span beam deflection capacity, according to the ANOVA results, an optimum SP/b ratio seems to be $0.25 \%$ for the both $\mathrm{w} / \mathrm{b}$ ratio (see Fig. 5 ). As also seen in Table $5, \mathrm{w} / \mathrm{b}$ ratio is statistically insignificant on the deflection capacity of the mixtures, which is in contrast with the finding of the results of Yang et al. [14]. In that study, Yang et al. mentioned that increase of $\mathrm{w} / \mathrm{b}$ ratio tends to improve the tensile strain capacity of ECC mixtures. The reason behind mentioned contrast can be the narrow design range of $w / b(0.27$ and 0.30$)$ ratio in the current research.

\subsubsection{Flexural strength}

Flexural strength test results and their statistical evaluations are given in Tables 4 and 5, respectively. As seen from Table 4, the average ultimate flexural strengths vary from 7.77 to 11.42 MPa at the age of 28 days. As shown in Table 5, flexural strength is influenced, in the order of contribution, by the $w / b$, $D_{\max }$, and $\mathrm{SP} / \mathrm{b}$. Parameter $\mathrm{s} / \mathrm{b}$ is statistically insignificant on the flexural strength variation of the ECC mixture under the limitations of current research. No distinctive variation in flexural strength depends on the $\mathrm{s} / \mathrm{b}$ parameter was discernible. ANOVA results demonstrate that $\mathrm{w} / \mathrm{b}$ is the most effective parameter on flexural strength with $81.9 \%$ contribution while the lowest is SP/b parameter with fairly nominal contribution (1.2\%). As clearly seen in Table 4 and Fig. 6, as expected, flexural strength decreases considerably as $w / b$ increases. The increase in the $w / b$ ratio means that there is more water between the solid particles and consequently there are more voids in hardened condition, increasing porosity and consequently leading to the decrease in the flexural strength [41]. The increase in maximum aggregate size $\left(D_{\max }\right.$ from $400 \mu \mathrm{m}$ to $1000 \mu \mathrm{m}$ ), for any given $\mathrm{w} / \mathrm{b}, \mathrm{s} / \mathrm{p}$ and $\mathrm{SP} / \mathrm{b}$ ratio, leads to a slight reduction in the flexural strength of ECC mixtures; most probably, due to the degraded distribution of PVA fibers in the case of sand with higher maximum aggregate size.

\subsubsection{Compressive strength}

The compressive strength test results of the ECC mixtures with varying $\mathrm{w} / \mathrm{b}, \mathrm{s} / \mathrm{b}, \mathrm{SP} / \mathrm{b}$ and $D_{\max }$ parameters are summarized in Table 4 , and assessment of those test results by analysis of variance are given in Table 5 . Compressive strength tests were performed on the ECC matrix and ECC specimens at 28 days. Six cubic specimens were tested for each mixture and average of them was presented. All ECC matrix and ECC mixtures showed compressive strengths higher than $38 \mathrm{MPa}$ at 28 days of age, and addition of PVA fiber to the ECC matrix did not considerably affect the test results. This value could significantly exceed that of normal concrete strength (30 MPa), and fulfill engineering requirements in most projects [14]. As seen in Table 5 and as expected, w/b is the most effective parameter on the compressive strength variation of ECC 

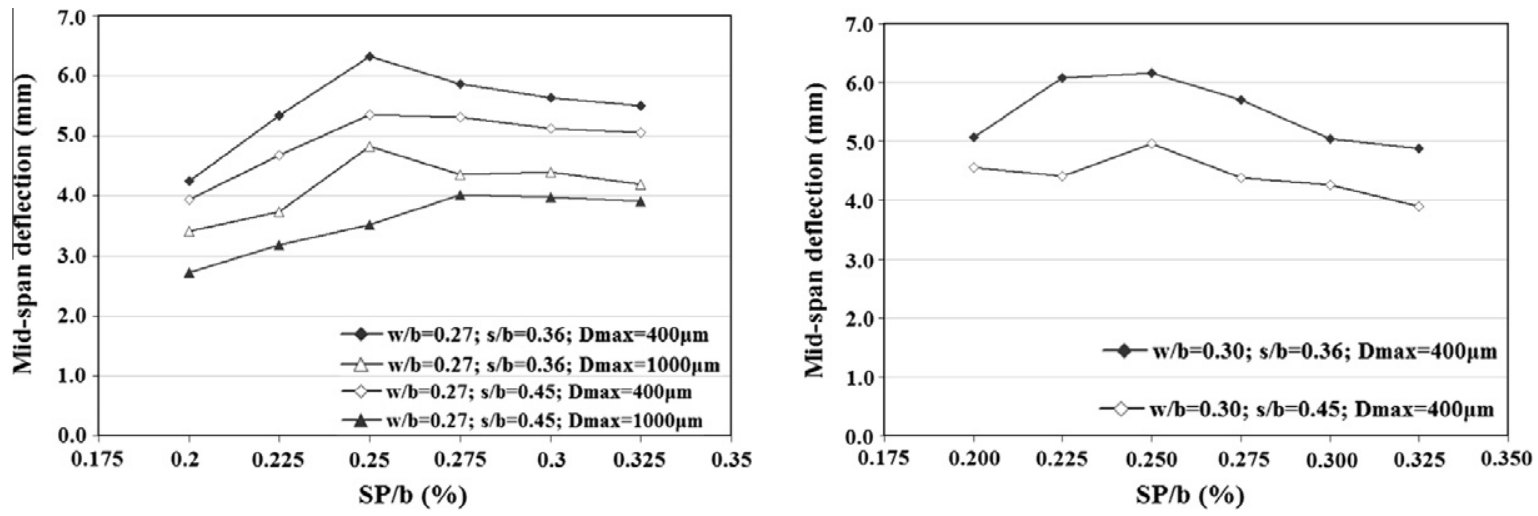

Fig. 5. Variation of mid-span beam deflection values.

specimens. Even a slight decrease in $\mathrm{w} / \mathrm{b}$ ratio (from 0.30 to 0.27 ) notably increased the compressive strength, and its percent contribution by ANOVA on compressive strength was around $90 \%$. w/b has multiple role to play in cement based composites' mechanical and durability properties such as decrease in $\mathrm{w} / \mathrm{b}$ ratio decreases the porosity, and concrete becomes more impermeable; lower $\mathrm{w} /$ $b$ ratio increases the strength of composites and hence improves their resistance to cracking from the internal stresses that may be generated by adverse reactions [42]. As seen from Tables 4 and 5 , an increase in the $D_{\max }$ and s/b parameters had no consistent effect in the compressive strength of ECC mixtures. Statistical analysis also confirmed that $D_{\max }$ is statistically insignificant on compressive strength and percent contribution of $\mathrm{s} / \mathrm{b}$ parameter is $4.5 \%$. This result is in contrast with the expectation: normally, compressive strength of cement based composites can be influenced by the aggregate size since a decrease in the aggregate size results in higher surface area for a given aggregate content, higher water requirement, [38] and therefore lower bond stress at a given load level [43]. However, in our case, variation of compressive strength due to the change of maximum aggregate size $\left(D_{\max }\right)$ was trivial. It has to be remembered that this conclusion holds for the range of aggregate sizes studied in the paper $(400-1000 \mu \mathrm{m})$. Gradual increase in $\mathrm{SP} / \mathrm{b}$ ratio did not greatly alter the compressive strength of ECC mixtures. There was no general ascending and descending trend in compressive strength due to the augmentation of SP/b ratio. Normally, it is well known that the paramount role of superplasticizer consists on a best dispersing effect of cement particles into the cement matrix by the adsorption of the chemical admixture molecules on the cement particles surface through the initial phase of hydration reactions $[44,45]$. This adsorption process improves the workability of the mix and reduces the water content in concrete mixture, which should improve the compressive strength [45]. According to the analysis of variance, contribution of $\mathrm{SP} / \mathrm{b}$ ratio on compressive strength was only $5.7 \%$.

\subsection{ECC mixture optimization}

\subsubsection{Regression models}

Multi linear regression models between the independent variables and the dependent responses were constructed. Before deciding what kind of regression models (linear, quadratic, cubic, etc.) were suitable for our data set, statistically significant and suggested models according to their computed $F$ and $p$-values were defined by using Design-Expert 7.0.3 statistical software package. For all the dependent variables (measured test results) only simple linear regression model was significant as follows:

$Y=a_{0}+a_{1}(\mathrm{w} / \mathrm{b})+a_{2}(\mathrm{~s} / \mathrm{b})+a_{3}(\mathrm{SP} / \mathrm{b})+a_{4}\left(D_{\max }\right)+E$
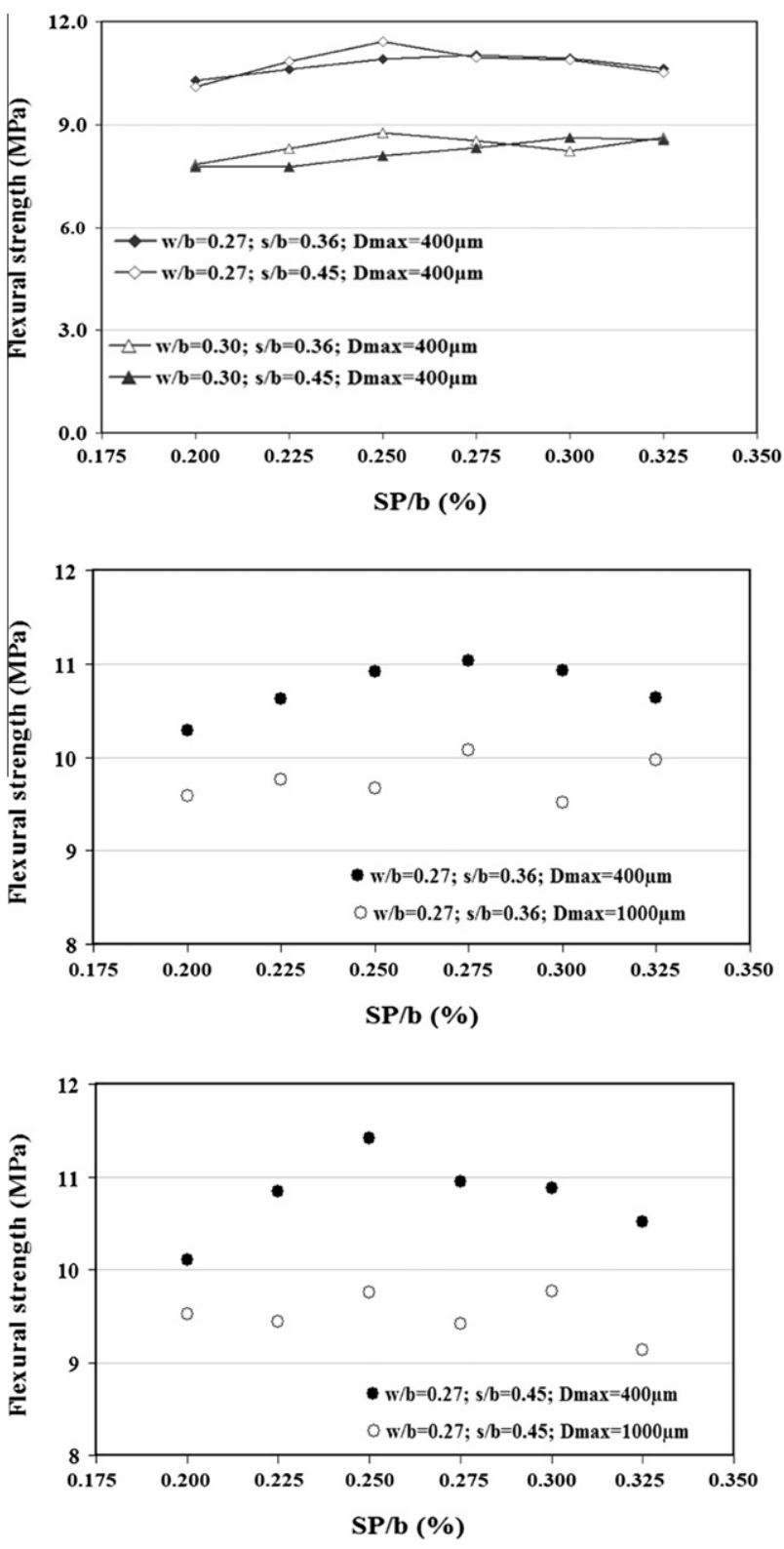

Fig. 6. Variation of flexural strength. 
Table 6

Dependent and independent parameters in the multi objective optimization problem.

\begin{tabular}{|c|c|c|c|c|}
\hline No. & Name of dependent and independent parameters & Goal & Lower limit & Upper limit \\
\hline 1 & $\mathrm{w} / \mathrm{b}$ & In range & 0.27 & 0.30 \\
\hline 2 & $\mathrm{~s} / \mathrm{b}$ & In range & 0.36 & 0.45 \\
\hline 3 & $\mathrm{SP} / \mathrm{b}(\%)$ & In range & $0.200 \%$ & $0.325 \%$ \\
\hline 4 & $D_{\max }(\mu \mathrm{m})$ & In range & 400 & 1000 \\
\hline 5 & Mini-slump flow diameter (\%) & Maximize & 96.5 & 404.5 \\
\hline 6 & Marsh cone flow time (s) & Minimize & 31.47 & 600 \\
\hline 7 & Yield stress $(\mathrm{Pa})$ & Minimize & 0 & 6.532 \\
\hline 8 & Plastic viscosity (Pa s) & Maximize & 0.252 & 1.7 \\
\hline 9 & Mid-span deflection (mm) & Maximize & 2.73 & 6.32 \\
\hline 10 & Flexural strength (MPa) & Maximize & 7.77 & 11.42 \\
\hline 11 & Compressive strength (MPa) & Maximize & 38.22 & 51.25 \\
\hline
\end{tabular}

Table 7

Optimum ECC mixture parameters, its expected test results and experimental results for optimum mixture proportions.

\begin{tabular}{|c|c|c|}
\hline Independent and dependent parameters & Optimum values and expected responses & Experimental results for optimum mix proportion \\
\hline $\mathrm{w} / \mathrm{b}$ & 0.27 & 0.27 \\
\hline $\mathrm{s} / \mathrm{b}$ & 0.36 & 0.36 \\
\hline $\mathrm{SP} / \mathrm{b}$ & 0.303 & 0.303 \\
\hline$D_{\max }$ & 400 & 400 \\
\hline Slump flow diameter ( $\mathrm{mm}$ ) & 348.60 & 357 \\
\hline Marsh cone flow time (s) & 31.47 & 34.84 \\
\hline Yield stress $(\mathrm{Pa})$ & 0.75 & 0.60 \\
\hline Plastic viscosity (Pa s) & 0.76 & 0.79 \\
\hline Mid-span deflection (mm) & 5.45 & 5.27 \\
\hline Flexural strength (MPa) & 10.90 & 10.73 \\
\hline Compressive strength (MPa) & 49.40 & 52.06 \\
\hline
\end{tabular}

In the above equation, coefficients $\left(a_{i}\right)$ represent the model constants (contribution of models parameters on the measured responses) and $E$ is random error term. The model constants are determined by multi-linear regression analysis and are assumed to be normal distributed [46]. After deciding the significant model for each dependent response, insignificant parameters in the significant model are then eliminated from the model. The derived models for mini slump flow diameter, Marsh cone flow time, yield stress, plastic viscosity, mid-span beam deflection capacity, flexural strength and compressive strength are presented with coefficient of correlation values in Table 5 . The derived models were obtained with $95 \%$ confidence interval. This signifies that there is less than $5 \%$ chance or $95 \%$ confidence limit that the contribution of a given parameter to the tested response exceeds the value of the specified coefficient [47]. The correlation coefficients of the proposed models for mini-slump flow diameter, Marsh cone flow time, yield stress, plastic viscosity, mid-span beam deflection, flexural strength and compressive strength are 0.978, 0.856, 0.901, $0.927,0.800,0.986$ and 0.864 , respectively. The high correlation coefficient of most responses demonstrates excellent correlation where it can be considered that at least $95 \%$ of the measured values can be accounted for the proposed models [47].

\subsubsection{Multi-objective optimization of ECC mixture proportioning and} verification experiment for optimum ECC mixture design

The independent parameters of the ECC mixture proportions were simultaneously optimized for the minimization of Marsh cone flow time and yield stress while for maximization of slump flow diameter, plastic viscosity, mid-span beam deflection capacity, flexural strength and compressive strength. A numerical optimization technique using desirability functions $\left(d_{j}\right)$ defined for each target response was utilized to optimize the responses [48]. To perform optimization studies, a statistical software package (Design-Expert 7.0.3) was used. To validate the statistical analysis, same calculation were also performed by using Minitab statistical software. Results of the both software was compatible with each other. In optimization using desirability functions, the general approach is to first convert each response $Y_{i}$ into an individual desirability function $d_{i}$ that varies over the range, $0 \leqslant d_{i} \leqslant 1$ where if response $Y_{i}$ is at its target value, then $d_{i}=1$, and if it is outside an acceptable region, $d_{i}=0$. Then the design variables were chosen to maximize the overall desirability as:

$D=\left(d_{1} x d_{2} x \ldots d_{m}\right)^{1 / m}$

where $m$ is the number of responses. A commercial statistical package was used for multi-objective optimization. For simultaneous optimization in statistical package, each response must have a low and high value assigned to each goal. Moreover, the goal field for responses must be one of choices, namely, none, maximum, minimum, target, or in range [49]. Factors will always be included in the optimization, at their design range by default, or as a maximum or minimum of target goal. For the simultaneous optimization process, the factors and responses were defined as in Table 6. At the end of the multi-objective optimization process, 56 different solutions which satisfied the specified constraints and limits could be obtained. The overall desirability of the functions ranged from 0.243 to 0.751 . Proposed ECC mix proportions with highest desirability value of 0.751 and their expected test results are given in Table 7.

In order to verify the theoretically obtained optimum ECC mixture design proportion, an experimental study was performed to check whether the minimization of Marsh cone flow time and yield stress while the maximization of slump flow diameter, plastic viscosity, mid-span beam deflection capacity, flexural strength and compressive strength achieved or not by the proposed optimum mixture proportion. In order to obtain meaningful results, the same materials and same conditions were used as in the main testing program. The test results can be seen in Table 7 . The verification study results showed that proposed optimum ECC mixture proportions satisfied the expected maximization for the compressive and flexural strength and mid-span beam deflection capacity. 


\section{Conclusions}

The influence of different combinations of water-binder (w/b), sand-binder (s/b), superplasticizer-binder (SP/b) ratios and maximum aggregate size $\left(D_{\max }\right)$ on the workability (mini slump flow diameter and Marsh cone time) and rheological properties (yield stress and plastic viscosity) of matrices (ECC w/o PVA fiber), and mechanical properties (compressive strength, flexural strength and mid-span beam deflection capacity) of ECC mixtures was investigated by means of design of experiments. The effects of studied parameters were characterized and analyzed using ANOVA and regression models, which can identify the primary factors and their interactions on the measured properties. To find out the best possible ECC mixture under the condition of this research concept for the desired workability, rheology and mechanical characteristics, a multi-objective optimization problem was defined and solved based on developed regression models. From the results obtained, the following conclusions can be drawn:

- $\mathrm{w} / \mathrm{b}, \mathrm{s} / \mathrm{b}$ and SP/b parameters are the significant parameters on the workability, and rheological properties of ECC matrices. Among these parameters, $\mathrm{SP} / \mathrm{b}$ ratio is appeared to be the most effective parameter. Therefore, in order to obtain ECC matrix with desired flowability, target yield stress and plastic viscosity, regulation of SP/b ratio is crucial. On the other hand, the alteration of maximum aggregate size from $400 \mu \mathrm{m}$ to $1000 \mu \mathrm{m}$ has slight or no effect on the workability and rheological properties of ECC matrices.

- The mid-span beam deflection capacities, which reflect material ductility, of ECC mixtures varied noticeably with the change of $\mathrm{s} / \mathrm{b}$ and $D_{\max }$ design parameters. Both of these two parameters negatively affect the deflection capacity of the ECC mixtures. The other parameters have almost no effect on the mid-span beam deflection capacities of ECC mixtures.

- ANOVA results demonstrate that the $\mathrm{w} / \mathrm{b}$ ratio is the most effective parameter on the flexural and compressive strengths variation of ECC mixtures, while the other parameters have much less effect compared to $\mathrm{w} / \mathrm{b}$ ratio.

- Fifty-six different optimum ECC mixture proportions were obtained at the end of the multi-objective optimization study. Mixture that has the highest desirability function value was experimentally produced, and it was seen that theoretically obtained optimum mixture proportions can be used to improve the rheological, workability and mechanical properties, and ductility of ECC.

\section{Acknowledgements}

The authors gratefully acknowledge the financial assistance of the Scientific and Technical Research Council (TUBITAK) of Turkey provided under Project: MAG-108M495.

\section{References}

[1] Proc. of the JCI international workshop on ductile fiber reinforced cementitious composites (DFRCCs); 2002.

[2] Kunieda M, Rokugo K. Recent progress on HPFRCC in Japan - required performance and applications. J Adv Concr Technol 2006;4(1):19-33.

[3] Lim YM, Li VC. Durable repair of aged infrastructures using trapping mechanism of engineered cementitious composites. Cem Concr Compos 1997;19(4):171-85.

[4] Fraternali F, Ciancia V, Chechile R, Rizzano G, Feo L, Incarnato L. Experimental study of the thermo-mechanical properties of recycled PET fiber-reinforced concrete. Compos Struct 2011;93:2368-74.

[5] D'Ambrisi A, Feo L, Focacci F. Bond-slip relations for PBO-FRCM materials externally bonded to concrete. Composites: Part B;2012;43(8):2938-2949.
[6] D’Ambrisi A, Feo L, Focacci F. Experimental analysis on bond between PBOFRCM strengthening materials and concrete. Composites: Part B; 2013;44(1):524-532.

[7] Cho CG, Kim YY, Feo L, Hui D. Cyclic responses of reinforced concrete composite columns strengthened in the plastic hinge region by HPFRC mortar. Compos Struct 2012;94(7):2246-53.

[8] Li VC. Engineered cementitious composites - tailored composites through micromechanical modeling. Fiber reinforced concrete: present and the future. In: Banthia N, Bentur AA, Mufti A, editors. Montreal, Quebec, Canada: Canadian Society for Civil Engineering; 1998. p. 64-97.

[9] Li VC, Wu C, Wang S, Ogawa A, Saito T. Interface tailoring for strain-hardening polyvinyl alcohol-engineered cementitious composite (PVA-ECC). ACI Mater J 2002;99(5):463-72.

[10] Wang S, Li VC. Engineered cementitious composites with high-volume fly ash. ACI Mater J 2007;104(3):233-41.

[11] Sahmaran M, Li VC. Influence of microcracking on water absorption and sorptivity of ECC. Mater Struct 2009;42:593-603.

[12] Maruta M, Kanda T, Nagai S, Yamamoto Y. New high-rise RC structure using pre-cast ECC coupling beam. Concr J 2005;43(11):18-26.

[13] Li VC, Lepech M, Li M. Field demonstration of durable link slabs for jointless bridge decks based on strain-hardening cementitious composites. Michigan Department of Transportation Research, Report RC-1471, December 2005. p. 265.

[14] Yang EH, Sahmaran M, Yang Y, Li VC. Rheological control in production of engineered cementitious composites. ACI Mater J 2009;106(4):357-66.

[15] Sahmaran M, Li VC. De-icing salt scaling resistance of mechanically loaded engineered cementitious composites. Cem Concr Res 2007;7(37):1035-46.

[16] Yang EH, Yang Y, Li VC. Use of high volumes of fly ash to improve ECC mechanical properties and material greenness. ACI Mater J 2007;104(6): 620-8.

[17] Li VC, Wang S, Wu C. Tensile strain-hardening behavior of PVA-ECC. ACI Mater J 2001;98(6):483-92.

[18] Kong HJ, Bike S, Li VC. Constitutive rheological control to develop a selfconsolidating engineered cementitious composite reinforced with hydrophilic poly(vinyl alcohol) fibers. Cem Concr Compos 2003;25(3):333-41.

[19] Ferraris CF, Obla K, Hill R. The influence of mineral admixtures on the rheology of cement paste and concrete. Cem Concr Res 2001;31(2):245-55.

[20] Banfill PFG. The rheology of fresh mortar. Magaz Concr Res 1991;43(154): 13-21.

[21] Bingham EC. US bureau of standards bulletin. Invest Laws Plast Flow 1916;13:309-53.

[22] Lachemi M, Hossain KMA, Patel R, Shehata M, Bouzoubaa N. Influence of paste/ mortar rheology on the flow characteristics of high-volume fly ash selfconsolidating concrete. Magaz Concr Res 2007;59(7):517-28.

[23] Khayat KH, Yahia A. Simple field tests to characterize fluidity and washout resistance of structural cement grout. Cem Concr Aggreg 1998;20(1):145-56.

[24] ASTM C109/C109M-11b standard test method for compressive strength of hydraulic cement mortars (using 2-in. or [50-mm] cube specimens).

[25] ASTM C78/C78M-10 standard test method for flexural strength of concrete (using simple beam with third-point loading).

[26] Pradhan B, Bhattacharjee B. Performance evaluation of rebar in chloride contaminated concrete by corrosion rate. Constr Build Mater 2009;23: 2346-56.

[27] Güneyisi E, Gesoglu M, Özbay E. Permeation properties of self-consolidating concretes with mineral admixtures. ACI Mater J 2011;108(2):150-8.

[28] Hicks CR. Fundamental concepts in the design of experiments. NewYork: Rinehart and Winston; 1982.

[29] Srinavasan CB, Narasimhan NL, Ilango SV. Development of rapid-set high strength cement using statistical experimental design. Cem Concr Res 2003;33(9):1287-92.

[30] Bjormstromz J, Chandra S. Effect of superplasticizers on the rheological properties of cements. Mater Struct 2003;36:685-92.

[31] Roussel N, Roy RL. The Marsh cone: a test or a rheological apparatus? Cem Concr Res 2005;35:823-30.

[32] Lu G, Wang K. Investigation into yield behavior of fresh cement paste: model and experiment. ACI Mater J 2010;107(1):12-9.

[33] Larrard FD, Ferraris CF, Sedran T. Fresh concrete: a Herschel-Bulkley material. Mater Struct 1998;31:494-8.

[34] Cyr M, Legrand C, Mouret M. Study of the shear thickening effect of superplasticizers on the rheological behavior of cement pastes containing or not mineral additives. Cem Concr Res 2000;30:1477-83.

[35] Feys D, Verhoeven R, Schutter GD. Fresh self compacting concrete, a shear thickening material. Cem Concr Res 2008;38:920-9.

[36] Safiuddin M, West JS, Soudki KA. Flowing ability of self-consolidating concrete and its binder paste and mortar components incorporating rice husk ash. Can J Civ Eng 2010;37:401-12.

[37] Lu G, Wang K, Rudolphi TJ. Modeling rheological behavior of highly flowable mortar using concepts of particle and fluid mechanics. Cem Concr Compos 2008;30:1-12.

[38] Mehta PK, Monteiro PJM. Concrete-structure, properties and materials. New York: Prentice-Hall; 1993.

[39] Senff L, Barbetta PA, Repette WL, Hotza D, Paiva H, Ferreira VM, et al. Mortar composition defined according to rheometer and flow table tests using factorial designed experiments. Constr Build Mater 2009;23:3107-11.

[40] Soroushian P, Nagi M, Hsu J. Optimization of the use of lightweight aggregates in carbon fiber reinforced cement. ACI Mater J 1992;89:267-76. 
[41] Haach VG, Vasconcelos G, Lourenço PB. Influence of aggregates grading and water/cement ratio in workability and hardened properties of mortars. Constr Build Mater 2011;25(6):2980-7.

[42] Mindess S, Young JF, Darwin D. Concrete. NJ: Prentice Hall; 2003.

[43] Cetin A, Carrasquillo RL. High-performance concrete: influence of coarse aggregates on mechanical properties. ACI Mater J 1998;95:252-61.

[44] Hsu KC, Chiu JJ, Chen SD, Tseng YC. Effect of addition time of a superplasticizer on cement adsorption and on concrete workability. Cem Concr Compos 1999;21(5-6):425-30.

[45] Meddah MS, Zitouni S, Belâabes S. Effect of content and particle size distribution of coarse aggregate on the compressive strength of concrete. Constr Build Mater 2010;24:505-12.
46] Yahia A, Khayat KH. Experimental design to evaluate interaction of high range water reducer and antiwashout admixtures in high performance cement grouts. Cem Concr Res 2001;31:749-57.

[47] Svermova L, Sonebi M, Bartos PJM. Influence of mix proportions on rheology of cement grouts containing limestone powder. Cem Concr Compos 2003;25:737-49.

[48] Bayramov F, Tasdemir C, Tasdemir MA. Optimization of steel fiber reinforced concretes by means of statistical response surface method. Cem Concr Compos 2004;26(6):665-75.

[49] Myers RH, Montgomery DC. Response surface methodology process and product optimization using designed experiments. John Willey \& Sons; 2002. 